\title{
The Teaching Design and Application of Online - Offline Hybrid Curriculum under the Influence of the Novel Coronavirus Pneumonia Epidemic
}

\author{
Wenjia Xie ${ }^{1 *}$, Kun Han ${ }^{1}$, Xiaoli Zhang ${ }^{1}$, Xinwei Gao ${ }^{1}$ and Meimei $\mathrm{He}^{1}$ \\ ${ }^{1}$ The Information and Communications College of National University of Defense Technology, Guangming Rd., Xi'an, 710106, China
}

\begin{abstract}
This paper analyzes the differences between online and offline courses in teaching organization, course content and practice, as well as the differences between hybrid teaching and hybrid courses in concept and emphasis. This paper puts forward the basic principles and requirements of hybrid courses teaching design, and discusses the key points and application scenarios of hybrid courses teaching design from three aspects: teaching objectives, teaching elements and teaching activities. And the key issues that need to be figured out are explained.
\end{abstract}

\section{Introduction}

Before the outbreak of the Novel Coronavirus Pneumonia Epidemic, online teaching was a supplement to the traditional form of higher education. It was usually an independent course, in parallel with traditional face-to-face teaching, such as online vocational education. There was no direct connection between the two teaching modes. With the rapid development of the Internet, especially the rapid development of smart phones and intelligent networks, online teaching has entered the classroom teaching in the past ten years. This historical evolution will inevitably bring about the hybrid teaching of online and offline courses. At the end of October 2019, the Ministry of Education issued the "Implementation Opinions on the Construction of First-class Undergraduate Courses", launching the "First-class Courses Double Ten Thousand Plan", and planned to open 6000 national-level online and offline first-class courses. In November 2019, the General Office of the Ministry of Education issued the Conducting the Recognition of National First-Class Offline, Online and Offline Hybrid, and Social Practice Undergraduate Courses in 2019, including a total of 1,000 online and offline hybrid courses. Due to the emergence of the Novel Coronavirus, in early February 2020 , in order to achieve the purpose of "the suspension of classes without suspension of teaching, suspension of classes without suspension of learning", the General Office of the Ministry of Education issued Guidance on the organization and management of online education in institutions of higher learning during the epidemic prevention and control period, and teachers and students of various colleges and universities started exploring online and offline hybrid teaching, which offered a good opportunity for accelerating the exploration of hybrid teaching.

\section{Understanding the difference between online teaching and classroom teaching accurately}

\subsection{Differences in teaching organization}

First, the difference in the number of students. The number of students learning online can range from one to infinity. Now, many apps for primary and secondary schools claim to be able to offer one-to-one tutoring, at the same time, hundreds of thousands of students can also learn together. For example, in MOOCs platform, the number of students learning a course in one semester can reach more than 300,000 . But the number of students in classroom teaching is limited by classroom capacity.

Secondly, the difference of learning environment. The online learning environment is a non-binding environment. Learners can study in any environment and any place with a mobile phone, while the classroom environment is an environment with clear discipline and time regulation. The difference brings about the difference of learners' mentality.

Thirdly, the difference in atmosphere of self-study. Students learn by the guidance of a teacher in the classroom, while they mainly rely on self-learning in face of handheld terminal, which takes the organizational form of teaching content into consideration. In [1], aiming at the learning and guidance in the hybrid virtual classroom, the author investigates the students' participation and test effect.

Finally, difference in teaching conditions and disciplines. The teaching conditions are restricted by the Internet, and the popularization of AI is obviously restricted by disciplines. For example, English classes

\footnotetext{
* Corresponding author's e-mail: liuxiangyang17@nudt.edu.cn,84375886@QQ.com
} 
and computer classes online teaching have been carried out very well [2]. However, more subjects and majors are still taught in the classroom, and the teaching environment of the classroom and the laboratory is more convenient for students to master teaching content. There is still difference between Internet teaching and classroom teaching which puts forward some requirements for teachers to carry out online classroom teaching.

\subsection{Differences in teaching content and teaching practice}

Due to the limitations of Internet teaching conditions, online courses are not simple relocation of the offline courses because not all courses and all parts of a course suitable for online teaching. Some courses cannot be carried out online unless they meet the three conditions: the content can be taught by a teacher; students own the necessary learning equipment, places and other external conditions; the learning effect can be assessed through online assessment. If a teacher can use language expression and PPT projection in the classroom to teach a course, in principle, it also can be carried out online. Some courses are not suitable for online teaching because they need more than oral expression and power point. Therefore, some offline courses cannot be shot directly and put into online to achieve the purpose of online teaching.

\subsection{Differences between hybrid teaching and online-offline hybrid courses}

Hybrid teaching refers to methodology. Even if there is no Internet in our classroom, the teacher may or has conducted hybrid teaching in the classroom for a long time. What is hybrid teaching? As long as it's not just the teacher speaking and the students listening in class to accomplish the teaching objectives, it's a hybrid course. Some courses are taught partly in the classroom and partly in the laboratory; teachers teach a part, and invite experts in related fields to communicate with students; students can read textbooks or watch video learning materials; flipped classroom. All of these are hybrid teaching. Therefore, the hybrid type is a kind of method, including hybrid teaching environment, hybrid teaching methods, hybrid teaching resources and hybrid teaching forms.

Online-offline hybrid courses refers to a learning process and a program during which students complete part of the content on the Internet. An important hallmark of online-offline hybrid courses is the allocation of content and class hours in both scenarios, not simply the allocation of methods. Therefore, online-offline hybrid courses have a teaching process with clear direction and objectives. MOOCs/SPOC is used for online teaching $[3,4]$, and hybrid teaching is also required for offline classes.

\section{The Teaching Design and Application of Online - Offline Hybrid Curriculum}

\subsection{Basic principles and requirements of online - offline hybrid curriculum}

The first basic principle of the application of hybrid course teaching design is to innovate classroom teaching activities. That is to say, there will be obvious changes between the classroom teaching before and after the occurrence of online teaching. The change is caused by the hybrid teaching design. The second basic principle is to take good advantage of online courses, so that it is not a simple sense of preview and review, otherwise, it will not be able to meet the requirements of online and offline hybrid teaching. Only the organic combination of online and classroom teaching activities can achieve twice the result with half the effort. There are three basic requirements. Firstly, online. According to the requirements of the documents of the Ministry of Education, teachers are expected to arrange $20 \% \sim 50 \%$ of the courses online. MOOC is not only a simple preview and review of the content, but also a clear definition of students' independent completion of a certain percentage of the course content so as to improve students' learning ability. Secondly, class. An innovative, efficient and dynamic classroom should be created to break the silence of the classroom, arouse the vitality and solve the key problems in class. Thirdly, tools. The use of informationalized teaching tools in the teaching and the in-depth integration of information technology and classroom teaching can solve the key problems in classroom teaching and realize the information management of the teaching process, and ultimately improve the teaching efficiency. As mentioned in [5,6,7], at the right time, through the appropriate information technology, we can provide students with appropriate resources and activities consistent with the appropriate learning conditions, so that students can obtain the best educational resources and learning methods, and obtain the best teaching effect.

\subsection{The key design points of online - offline hybrid curriculum}

First of all, the division of teaching scenes should be considered. The teaching contents are carried out separately in appropriate teaching scenes, including offline classroom scenes and online scenes. It's important to notice that the teaching content in these two scenes should not be mostly repeated or completely repeated. There should be relatively obvious differences between them. Part of the contents will be taught online and part of the content will be taught in class. They can be crossed or repeated, but they cannot be completely crossed or iterated, otherwise the requirements of online and offline hybrid teaching cannot be met.[8] 


\subsection{Goal setting of online - offline hybrid curriculum}

The online teaching objectives must be distinguished from the classroom teaching objectives. There can be repetitions but there must be a clear distinction; the online hours and the classroom hours must be relatively independent, and the learning time of students is fixed. The hours allocated to students for each course should be reasonable and appropriate to achieve the teaching goals. Both online time and offline time belong to teaching time. The sum of these time is teaching time. The teacher must clarify the relationship between the three elements of content, goal and time, and clearly divide them. This is a planning issue. That is to divide the content, goals, and time of teaching as a whole, and then complete the teaching purpose in the specific scenarios. As discussed in [9], a great curriculum should have a clear goal distinction.

\subsection{The teaching elements of the online course}

The teaching elements of online courses run through the teacher's guidance and teaching process. The elements include short lecture videos, in-class exercises, interactive communication, homework tests, Q\&A discussions, assessment and evaluation. They are all teaching elements of online teaching, so mere video recording and broadcasting is not enough to constitute an online course. An online course needs more and richer teaching elements. It is difficult to teach a class well for students to enjoy, but the most difficult point is to set a series of questions carefully to evaluate the teaching of students. The design of activities is more difficult than deliver a class.

\subsection{Teaching activities of offline classroom}

The teaching elements of offline classroom include teaching philosophy, teaching objectives, teaching design, teaching content, teaching organization, management and evaluation. In hybrid teaching activities, the teaching objectives of offline classrooms pay more attention to classification guidance; the teaching design pays more attention to ability training, activity series and multiple evaluations; the teaching content covers knowledge, skills and emotion, attitude and value; the teaching organization flexibly integrates the application of information technology and classroom teaching; the management evaluation should guarantee that teaching process can be traced back and measured. The changes also put forward requirements for the reform of offline classrooms in the following three aspects:

Content. With the development of online classroom, due to the distribution of content and goals, much time and foundation have been relatively gained for offline classrooms, allowing teachers to enrich classroom teaching content to attract students' face-to-face teaching, focusing on improving students' comprehensive abilities and reshaping the curriculum. Offline and online teaching content are integrated together to form the whole teaching content.

Active. Classroom teaching activities are very important to improve the vitality of the classroom and the efficiency of the classroom. It is necessary to turn classroom teaching into a classroom where students are willing to learn, like to learn, and mobilize their enthusiasm. Innovating teaching methods and breaking the original silent and cramming classroom can rejuvenate the classroom with vitality.

Efficiency. Solving the key and difficult problems of teaching and learning and the clear and effective teaching effect are the most important signs of evaluating the efficiency of classroom teaching.

Hybrid curriculum teaching, along with the development of online classrooms, will gain more time for offline classrooms to carry out more effective activities, so that students are interested in learning and teachers teach efficiently [10]. This kind of classroom is what online - offline hybrid curriculum requires. If students are allowed to learn the content of the course online, and the offline teacher still speaks as before, then the purpose of teaching reform will not be achieved. Of course, under the influence of the novel coronavirus pneumonia epidemic, the online - offline hybrid curriculum is a special case. There is no classroom and only online teaching can be used. Once the teaching under the epidemic is taken into consideration, it is an activity that relies more on online teaching. It needs to carry out well the teaching process such as short video lectures, classroom exercises, interactive communication, homework tests, Q\&A discussions, assessment and evaluation. From the perspective of hybrid teaching, the design of classroom teaching must be attached great importance.

\subsection{Application scenario of online - offline hybrid curriculum}

Personalized learning methods can be used online, such as short videos, online live broadcasts, mutual evaluation assignments, online tests and online discussions to deliver knowledge. Offline classrooms can use flipped classrooms to complete knowledge internalization, such as inquiry, question, project, cooperation and seminar to set students' learning tasks. There can be more application scenarios. If the learning of knowledge is completed in offline classrooms, complex and inquiring leaning online is also possible, which also refers to the specific requirements of this course in the school's talent training plan and the teaching purpose of the teacher. Different scenes can be arranged according to different teaching objectives.

\section{Key Issues of Online - Offline Hybrid Curriculum}

\subsection{Designing specific curriculum objectives}


Both the online part and the offline part of the course goal are narrowly defined, referring to a specific course. In some aspects of the talent training program, the course cultivates limited, clear and professional abilities. All course objectives must be measurable and achievable. In addition to the knowledge objectives that can be measured by the exam, the course objectives also include humanistic objectives, moral objectives, and value objectives. The design of course objectives must have a certain degree of high-level and challenge. High-level refers to ability training, challenge refers to difficulty.

\subsection{Classified guidance on course design}

After the first-class curriculum construction started last year, it began to emphasize classified guidance, that is, the school should set up its own curriculum design according to its own talent training plan/talent training goals, rather than simply imitating and comparing others. Under the principle of classified guidance, the goal of personnel training should be achieved first, and then students' classroom vitality and teaching efficiency should be fully enhanced under the condition of information technology, and teachers' teaching ability should be supplemented and improved through the integration of information technology.

\subsection{Schools should strengthen teaching process management}

After carrying out online teaching or hybrid teaching, the management of the school must be strengthened. Now different schools are carrying out hybrid teaching, but the following points are relatively weak and need to be further improved:

Professional talent training program. The orientation of the curriculum in the talent training plan/talent training goal, and the relevant activity plan of social practice courses should be figured out. Teaching calendar (planning). It can be completed by means of information systems, including: time, place, content, activities, class hours, online, practice, records and other elements. Lesson plan. Now that people have entered the PPT era, most teachers do not make teaching plans (handouts), but the teaching plans actually contain more content than PPT, which also contains a lot of spoken words and main points. Using the same PPT, the effect of lectures varies greatly.

Student learning data online. Both online courses and online-offline hybrid courses clearly require students' online learning records. Such records are not only grades, but also process data, such as how many assignments were done, how many discussions were taken, how many discussions were held, and other comprehensive information.

Video of class or practice sessions. The first-class courses should be entered into the smart classroom as far as possible. Actual recording is an effective means of classroom traceability, measurement and evaluation. It can record the whole classroom teaching and online teaching activities, and play a supervisory role at the same time.

\section{Conclusions}

With the appearance of novel coronavirus, online teaching has once again displayed its vitality. The application of online-offline hybrid courses has introduced online learning into the classroom teaching process, broken the original teaching objectives, teaching elements and the arrangement of teaching activities, and proposed more demands and opportunities for the application of new scenarios. Colleges and universities should make full use of excellent online resources, seize opportunities, change ideas, promote the reform of teaching mode, turn the network platform for spreading knowledge into a tool for internalizing knowledge, integrate extensive online and offline resources, and create first-class courses with the characteristics of new educational formats.

\section{References}

1. Annelies, R., Pieter, V., Marieke, P., Ine, W., Noortgate, V. D., Fien, D.(2020) Learning and instruction in the hybrid virtual classroom: An investigation of students' engagement and the effect of quizzes. Computers \& Education, Vol.143,0360-1315.

2. Liu, T., Kim, E., Li, X.Y., Yuizono, T., Nagai, Y., Lu, Y.F. (2020) Research and Practice of Hybrid Teaching Based on AI technology for Foreign Language Translation. 2020 International Conference on Computer Engineering and Application (ICCEA), 664-668.

3. Nikola, L., Goran, S., Jelena, S., Branko, M.(2019)A Framework for Teaching Security Design Analysis Using Case Studies and the Hybrid Flipped Classroom. ACM Transactions on Computing Education, Vol.19.

4. Bafna, Kailash, M.(2015) Using Emerging Technologies for Hybrid and Flipped Classroom Learning. Proceedings of the ASEE Annual Conference \& Exposition, 1-10.

5. Jennifer, H. (2008) "Blended learning Case Study [EB/OL]".

http://www.learningcirts.org/2001/apr2001/ hofmann,

6. Li, F. Q. (2016) "The Theoretical Basis and Teaching Design of Blended Teaching". Modern Educational Technology, 9:18- 24.

7. Wang, J., Yang, Z.(2017) "Design of Blended Teaching Mode Based on Cloud Class-Taking Cloud Class in Central China Normal University as an Example". China Educational Technology, 4:85- 89.

8. Qu, D., Liu, M., Xu, H.J., Cao, H. (2020) Discussion on Online and Offline Hybrid "Golden Course" Teaching Mode and Curriculum Construction. The Science Education Article Cultures, 17: 49-50. 
9. Wu, Y. (2018) Building China's "Golden Lessons". China University Teaching, 12:4-9.

10. Xiao, H.Q. (2016) Thinking and exploration of "online and offline" teaching mode. Vocational Technology, 7:17-18. 